\title{
ARQUEOLOGIA E HISTÓRIA DA REPRESSÃO NA DITADURA MILITAR BRASILEIRA: ALGUNS ASPECTOS SOBRE A GUERRILHA DO ARAGUAIA
}

\section{PATRICIA SPOSITO MECHI}

Instituto Latino-americano de Economia, Sociedade e Política da Universidade Federal da Integração Latino-americana - ILAESP/UNILA patricia.mechi@,unila.edu.br

\section{Resumo:}

Este artigo busca apresentar uma reflexão sobre as possibilidades de atuação interdisciplinar nos estudos sobre as ditaduras, a partir do caso concreto da guerrilha do Araguaia. No entanto, preliminarmente, tecemos considerações sobre a natureza fragmentária e lacunar da documentação produzida pelas ditaduras e em alguns casos, sua deliberada destruição. Entendendo que esta ocultação das fontes históricas/provas dos crimes de lesa-humanidade faz parte da lógica do sistema repressivo desenvolvido no período, apresentamos em linhas gerais sua estrutura, tal como desvendada pela Comissão Nacional da Verdade para apenas então pontuar aspectos do caso da guerrilha do Araguaia.

\section{Palavras-chave:}

Arqueologia, história, guerrilha do Araguaia, repressão, ditadura militar.

\begin{abstract}
:
This article seeks to present a reflection on the possibilities of interdisciplinary action in the studies on dictatorships, starting from the concrete case of the Araguaia guerrilla. However, we preliminarily make considerations about the fragmentary and incomplete nature of the documentation produced by dictatorships and in some cases, their deliberate destruction. Understanding that this concealment of historical sources / evidence of crimes against humanity is part of the logic of the repressive system developed during the period, we outline its structure, as revealed by the National Truth Commission, only to punctuate aspects of the guerrilla case of Araguaia.
\end{abstract}

\section{Keywords:}

Archeology, history, Araguaia guerrilla, repression, military dictatorship. 


\title{
ARQUEOLOGIA E HISTÓRIA DA REPRESSÃO NA DITADURA MILITAR BRASILEIRA: ALGUNS ASPECTOS SOBRE A GUERRILHA DO ARAGUAIA
}

\author{
PATRICIA SPOSITO MECHI \\ Instituto Latino-americano de Economia, Sociedade e Política da \\ Universidade Federal da Integração Latino-americana - ILAESP/UNILA \\ patricia.mechi@,unila.edu.br
}

\begin{abstract}
"Amarildo de Souza, 43 anos, foi levado para a sede da UPP (Unidade de Polícia Pacificadora) da Rocinha, favela da zona sul do Rio de Janeiro, na noite de domingo, 14 de julho. "Para averiguação", como a polícia costuma dizer quando carrega com ela algum pobre, como se fosse uma justificativa aceitável. (...)Amarildo acabara de voltar de uma pescaria quando quatro policiais o abordaram, supostamente confundindo-o com um traficante, embora testemunhas digam que pelo menos um deles o conhecia muito bem. Nos dias 13 e 14 de julho, a "Operação Paz Armada" - e aqui o nome não é apenas uma ironia, mas também uma violência - colocou 300 policiais na Rocinha e prendeu dezenas de pessoas. (...) Amarildo entrou no carro da Polícia Militar vestindo apenas bermuda e chinelos. (...) Desde então, não foi mais visto."

"Con una imagen sonriente de los ministros Patricia Bullrich y Germán Garavano el Gobierno convocó a una transmisión en vivo a través de Facebook, donde los funcionarios a cargo de los ministerios de Seguridad y Justicia y Derechos Humanos prometieron "contestar en vivo" las consultas de los usuarios. El objetivo era contestar preguntas sobre "sobre la lucha contra el narcotráfico y la nueva Ley de Flagrancia", pero en las redes los usuarios se autoconvocaron para hacer una única pregunta: ¿Dónde está Santiago Maldonado?"2
\end{abstract}

Os dois trechos anteriores forma retirados de notícias sobre os desaparecimentos recentes nos regimes pós-ditatoriais de Brasil e Argentina, respectivamente. O primeiro, Amarildo, desaparecido sob custódia do Estado, provocou intensa comoção popular e tornava notícia aquilo que a população mais pobre do Brasil já sabia: práticas de detenção arbitrária, tortura e desaparecimentos forçados não deixaram de acontecer com o final da ditadura militar, entretanto, não se tratam de resquícios de um passado já superado e sim mais um dado na longa lista de comprovações de que a máquina repressiva do regime ditatorial não foi desmontada. O segundo, Santiago Maldonado, um lutador social argentino que protestava em favor dos Mapuches, foi visto com vida pela última vez com vida sendo agredido pela polícia. Seu cadáver foi encontrado 78 dias depois, e a versão oficial afirma que ele morreu por afogamento.

Ambos os casos demonstram que mesmo em países que enfrentaram seu passado ditatorial com punição dos culpados, com a Argentina, ou aqueles que ainda não o fizeram, como o Brasil, mas que realizam políticas de memória, com o resgate histórico de um passado traumático, e que

\footnotetext{
1 BRUM, Eliane “Onde está o Amarildo?" Época on-line, 05 de agosto de 2013, disponível em: https://epoca.globo.com/colunas-e-blogs/eliane-brum/noticia/2013/08/onde-esta-bamarildob.html, acessado em 08 de setembro de 2018.

2 “¿Dónde está Santiago?” El País, 23 de agosto de 2017, disponível em https://www.pagina12.com.ar/58314donde-esta-santiago, acessado em 9 de setembro de 2018.
} 
realizam, ainda, trabalhos na área da psicologia com as vítimas, não estão isentos da permanência de práticas sistemáticas de violação dos direitos humanos.

Enfrentar esse passado doloroso, com tantas chagas ainda abertas, não é tarefa fácil, mas é urgente e necessário aprofundar continuamente os estudos que decifram os mais variados aspectos das ditaduras, entre elas o funcionamento das máquinas repressivas, seus agentes, estratégias e continuidades, além de combater as políticas de esquecimento e continuar a identificar e punir os culpados nos países que já o fazem e iniciar, naqueles em que ainda não há nenhum preso pelos crimes lesa-humanidade cometidos nos anos de chumbo.

Desvendar o funcionamento dos aparatos repressivos, avançar na compreensão das linhas de permanência deste passado no presente permite fortalecer as políticas de enfrentamento à violência estatal, garantindo o desenvolvimento de instrumentos garantidores do respeito aos direitos humanos. A partir de preocupações como as descritas anteriormente este artigo busca, numa abordagem interdisciplinar, discutir alguns aportes que a arqueologia pode oferecer ao trabalho de resgate do passado. Para isto, fazemos um breve resgate da atividade repressiva desenvolvida na ditadura brasileira, e os desafios que envolvem o estudo de um tema cujos principais agentes se esforçaram para ocultar sua existência. Procuramos indicar como a arqueologia pode, numa atividade de estudos interdisciplinar, ajudar a iluminar aspectos onde a documentação escrita não existe ou, por outro lado, confrontar com os vestígios materiais, o discurso da "não existência" de torturas, desaparecimentos ou centros clandestinos de tortura. Por fim, apresentamos de maneira sucinta como a arqueologia pôde esclarecer alguns aspectos e enriquecer os estudos sobre a guerrilha do Araguaia.

\section{Introdução}

A arqueologia com disciplina científica nasceu vinculada à expansão imperialista no século XIX e a um projeto de poder cujo centro dinâmico se situava na Europa Ocidental. Também estava diretamente relacionada à constituição dos Estado-nação europeus, fornecendo, assim como a História, a criação de uma narrativa sobre o passado que apontasse aquela região do mundo como a mais desenvolvida civilização existente.

Originalmente concebida como ciência das coisas antigas (do grego, archaio logos), a arqueologia buscou resgatar o passado das chamadas grandes civilizações, consideradas como origem da Europa Ocidental, tais como Grécia, Roma, mas também o Egito, que apesar de situado na África, fez parte de um passado imaginado pelos europeus, o qual a arqueologia ajudava a glorificar por meio das descobertas de tumbas com joias, múmias, riquezas, ruínas de templos, palácios, entre outras coisas. Este passado greco-romano já havia sido recuperado e valorizado no Renascimento, herança que teria sido esquecida nos anos de Idade Média. Além de contribuir na construção de uma narrativa histórica sobre o passado, a arqueologia também foi um instrumento de hierarquização das sociedades humanas, cuja culminância era sempre a Europa Ocidental.

Podemos entendê-la como uma ciência que compôs o arsenal ideológico europeu moderno que se desenvolveu, a partir do século XVI, com a conquista da América. Muitos autores, ao estudar a mentalidade europeia na conquista, apontava que estes apresentavam uma concepção de superioridade em relação aos povos originários da América, que foram pelos europeus homogeneizados sob a denominação de "indígenas." Diversas comunidades foram descritas de acordo com a classificação das sociedades ditas pré-históricas: Paleolítico inferior/superior, Mesolítico, Neolítico e etc. Estranhamente, comunidades vivas eram classificadas de acordo com preceitos utilizados para designar sociedades já extintas.

\footnotetext{
${ }^{3}$ TODOROV, Tzetan, A Conquista da América: a questão do outro, São Paulo, Martins Fontes, 2016.
} 
Dessa forma, ao mesmo tempo em que os arqueólogos contribuíam para a constituição da ideia de um passado comum, escavando em sítios com centenas ou milhares de anos - que teriam ligação como os europeus pela cultura ou pela localização geográfica, também estabeleciam em relação aos outros povos do mundo, sua pretensa superioridade.

Se, durante muito tempo a arqueologia esteve ligada exclusivamente à um projeto de poder das classes dominantes, apresentando posições conservadoras ou francamente reacionárias e atuado como instrumento de legitimação da dominação burguesa, hoje ela encontra outros usos. Apesar de não ter deixado de lado totalmente a epistemologia desenvolvida no século XIX, a arqueologia passou também a ser entendida também como uma ferramenta que permite resgatar histórias de grupos que foram silenciados, que sofreram violências ou desenvolveram formas de resistência.

Nos anos recentes a arqueologia passou a ser cada vez mais convocada à auxiliar no atendimento de demandas postas por comunidades marginalizadas, movimentos sociais e vítimas de violência do Estado, entre outros grupos que recorrem à arqueologia para recuperar seu passado. Dessa forma, esta ciência apresenta uma importante contribuição para a afirmação dos direitos dos povos, para o combate ao machismo, o patriarcalismo, o racismo, recuperando histórias de violência, mas também de resistência.

A arqueologia da repressão e da resistência é um campo novo de estudos, ligado precipuamente aos regimes ditatoriais latino-americanos que se desenvolveram na segunda metade do século $\mathrm{XX}$, sob a égide da guerra fria. Este campo se vincula à uma mudança paradigmática e teórica que vem ocorrendo na área nos últimos 30 anos, permitindo que a arqueologia aporte seus saberes e métodos para compreender problemas do presente. Se antes, a arqueologia era a ciência do passado mais distante da humanidade, resgatando a história de comunidades sem escrita, hoje ela pode contribuir em qualquer estudo em que seja possível a análise da cultura material, não importando qual a distância temporal que separa o pesquisador do objeto de estudo. É, inclusive, uma ciência cujo objeto pode se encontrar no presente.

A possibilidade da constituição de um campo de estudos voltado para a arqueologia da repressão e da resistência nos regimes ditatoriais latino-americanos passou a se concretizar a partir da atuação da equipe de arqueologia forense argentina, respondendo à demandas colocadas pela sociedade civil, em particular pelos familiares dos desaparecidos políticos naquele país.

No Brasil esta mesma equipe foi essencial para impulsionar a atividade arqueológica na busca pelos desaparecidos políticos. Assim como na Argentina, tratou-se de uma atividade que não nasceu na academia, e sim da ação do Estado, demandado pelas ações de familiares de desaparecidos políticos. A academia passou a ter seus profissionais da área de arqueologia solicitados a colaborar com as pesquisas que objetivavam o esclarecimento das circunstâncias das mortes e dos desaparecimentos de opositores políticos das ditaduras militares e, posteriormente, criou-se um campo de estudos, que tem na publicação do livro "Arqueologia da Repressão e da Resistência" " o que poderia ser considerado um marco inaugural desses esforços.

\section{História e arqueologia combatendo silêncios}

Se há uma prática comum às ditaduras militares da América Latina, que tiveram lugar na segunda metade do século XX foi um esforço, com menor ou maior intensidade, por ocultar os crimes de lesa-humanidade cometidos não apenas contra militantes de esquerda, mas também contra a população comum. No Brasil, a Doutrina de Segurança Nacional, preconizando que a pobreza podia ser um fator de desestabilização do regime e, portanto, os pobres deveriam ser reprimidos preventivamente, numa lógica que considera a pobreza subversiva, se abateu largamente sobre

\footnotetext{
${ }^{4}$ FUNARI, Pedro Paulo; ZARANKIN, Andrés \& REIS, José Alberioni dos, Arqueologia da repressão e da resistência:
} América Latina na era das ditaduras (décadas de 1960-1980), São Paulo, AnnaBlume/FAPESP, 2008. 
trabalhadores, camponeses, indígenas e diversos outros grupos sociais que não tinham qualquer relação com a militância de esquerda. ${ }^{5}$

Os sistemas repressivos na América Latina tinham profundas interconexões, consubstanciadas na Operação Condor - apenas uma das diversas atividades de um sofisticado sistema repressivo continental, inspirado na Doutrina de Segurança Nacional estadunidense e na Doutrina da Guerra revolucionária Francesa. ${ }^{6}$ Os países membros intercambiaram não apenas informações, mas também presos políticos, métodos de tortura, agentes, além de realizarem operações conjuntas, em comandos composto por militares de diversas nacionalidades. O sigilo era considerado vital para as operações, assim como, a sistemática negação da existência de torturados, desaparecidos sob a responsabilidade do Estado, centros clandestinos de tortura e detenção, entre outros.

As forças repressivas legais - polícias e Forças Armadas e suas instalações atuavam em simbiose com uma estrutura ilegal e clandestina, composta por uma rede de imóveis comerciais e residenciais, urbanos e rurais, para onde eram levados os presos que muitas vezes desapareciam.

Mesmo durante as ditaduras, foi negada a existência destes locais, assim como foram negadas a as interconexões internacionais entre os sistemas repressivos nacionais, podendo-se falar atualmente em um sistema continental, de torturadores a mando do Estado e desaparecimento de pessoas nos anos de ditadura.

Somando-se à pratica de negar tais fatos, ao final da ditadura militar brasileira, por exemplo “ foram feitos mutirões em delegacias para desaparecer com indícios comprometedores, destruiu-se documentos em órgãos públicos e as instituições militares recusam-se, até os dias atuais, em disponibilizar seus arquivos do período". ${ }^{7}$

Entretanto, mesmo negando a existência de tortura, desaparecimentos e outras ações de repressão, foi impossível aos agentes da repressão recolher e destruir todo o volume provas dos crimes cometidos no período, já que a replicação de documentos era próprio da dinâmica dos setores de informação das Forças Armadas. Um exemplo disso se refere à guerrilha do Araguaia, que os militares, durante muito tempo, negaram que tivesse existido, contudo, os relatórios da repressão à guerrilha foram enviados a 21 locais diferentes, entre Exército, Marinha, Aeronáutica, ministérios, inclusive, o ministério da Educação. ${ }^{8}$

Mesmo contando com um volume importante de informações, nelas não estão explícitas a maior parte dos crimes de lesa-humanidade, sendo possível apenas "garimpar" indícios deles. Havia um conjunto de práticas que não deveriam deixar nenhuma espécie de registro, desaparecendo, inclusive, com os corpos daqueles que passaram pela estrutura ilegal de repressão. As práticas de tortura, prisões arbitrárias e desaparecimentos, ao não deixarem registros escritos e, em muitos casos, sequer corpos, só puderam vir à tona por meio principalmente dos testemunhos dos sobreviventes. São estes depoimentos que permitem conhecer a existência de locais clandestinos, ocultos na estrutura legal de repressão. A Comissão Nacional da Verdade apurou a existência de pelo menos 17 centros clandestinos de tortura e desaparecimento.?

\footnotetext{
${ }^{5}$ Mechi. Patricia Sposito. “As Forças Armadas e a barbárie no Araguaia: a repressão à guerrilha entre 1972 e 1974 ”. Catalão, Revista Opsis, jan/jun 2014, pp. 101-119.

'SILVA, Jussaramar, As conexões repressivas no cone sul (1960-1990): Terrorismo de Estado em conexão internacional, Doutorado em História Social, Sâo Paulo, Pontifícia Universidade Católica de São Paulo, 2016.

${ }^{7}$ MECHI, Patricia S. \& JUSTAMAND, Michel, “Arqueologia em contextos de repressão e resistência: a guerrilha do Araguaia”, Revista de Arqueologia Pública, Campinas, Unicamp, dezembro de 2014, pp. 108-120.

${ }^{8}$ MECHI, Patricia Sposito, Protagonistas do Araguaia: camponeses, militantes e militares na Guerrilha. Rio de Janeiro, Arquivo Nacional, 2015.

${ }^{9}$ COMISSÃO NACIONAL DA VERDADE, "Instituições e locais associados à graves violações dos direitos humanos" in: Relatório Final da Comissão Nacional da Verdade, pp.728-839, disponível em: http://www.memoriasreveladas.gov.br/administrator/components/com_simplefilemanager/uploads/CNV/relat $\%$ C3\%B3rio\%20cnv\%20volume_1_digital.pdf, acessado em: 20 de agosto de 2018.
} 
O testemunho muitas vezes é a única fonte de informação de que dispõem os pesquisadores, e é ela quem pode descortinar um centro clandestino de detenção, para o qual a arqueologia pode contribuir sobremaneira. Um exemplo disso é a comprovação da existência da casa da morte, através do testemunho de sua única sobrevivente, Ettiene Romeu; seu testemunho, cotejado com testemunhos de agentes da repressão, permitiu descobrir a localização deste centro de clandestino de repressão que, segundo o relatório final da CVN, "foi um dos principais centros clandestinos utilizados pelo regime militar para a prática de graves violações de direitos humanos: detenção ilegal e arbitrária, tortura, execução e desaparecimento forçado."10

Faz parte do ofício do historiador - e também do arqueólogo - entre outras ciências humanas, lidar com registros lacunares das sociedades humanas, pelos mais diversos motivos, desde o descaso do poder público, provocando verdadeiras tragédias para a memória nacional ${ }^{11}$ até a ausência de registros sobre determinados aspectos das práticas sociais porque estas não deveriam se tornar conhecidas nem pelos contemporâneos, nem pela posteridade, na visão dos setores dirigentes da sociedade. Até pouco tempo atrás o caso mais conhecido e escandaloso de destruição documentos históricos tinham sidos os documentos relativos à escravidão, que foram queimados por ordem do Ministro da Fazenda, Ruy Barbosa, em 1890, durante o governo de Deodoro da Fonseca, primeiro presidente do Brasil após o fim da monarquia.

Já há algumas décadas a noção de documento histórico se ampliou sobremaneira, abarcando, potencialmente toda a produção humana, enriquecendo o campo da pesquisa histórica. Contudo, se o documento escrito oficial perdeu a exclusividade, certamente não deixou de ser também importante já que, para certos objetos e temas, em particular aqueles se centram no estudo do Estado, nas práticas de instituições ou governos, a documentação oficial - evidentemente abordada de maneira crítica - tem valor inestimável.

$\mathrm{Na}$ ausência de registros escritos, que podem ter sido deliberadamente destruídos ou sequer produzidos para ocultar práticas criminosas, uma série de outras fontes podem ser utilizadas e neste campo, a arqueologia oferece uma importante contribuição, em particular, a arqueologia histórica, que estuda vestígios os humanos mais recentes.

\section{A estrutura repressiva da ditadura brasileira}

Em 2012, foi instituída no Brasil a Comissão Nacional da Verdade, que tinha como objetivo "apurar graves violações de direitos humanos ocorridas entre 18 de setembro de 1946 e 5 de outubro de 1988." 12 A criação da CNV ensejou a criação de diversas comissões estaduais, municipais, de entidades como sindicatos, além de comitês independentes da ação do estado.

A partir dos estudos da Comissão Nacional da Verdade e dos depoimentos das vítimas da ditadura, foi possível aprofundar o entendimento da estrutura repressiva brasileira, além de mapear diversos centros clandestinos de tortura e morte em todo o país. A seguir, apresentaremos brevemente a estrutura repressiva desvendada pela CNV.

Entendemos, como Padrós, que a ditadura brasileira atuou segundo a lógica do Terrorismo de Estado que, de acordo com este autor,

\footnotetext{
1010 COMISSÃO NACIONAL DA VERDADE, "Desaparecimentos Forçados” in: Relatório Final da Comissão Nacional da Verdade, p 532, disponível em:

http://www.memoriasreveladas.gov.br/administrator/components/com_simplefilemanager/uploads/CNV/relat $\%$ C3\%B3rio\%20cnv\%20volume_1_digital.pdf, acessado em: 20 de agosto de 2018.

11 Por exemplo, o incêndio que destruiu o Museu Nacional, no Rio de Janeiro, no dia 2 de setembro de 2018.

12 BRASIL, Lei 12.528 de 12 de novembro de 2011.
} 
“se fundamenta na lógica de governar mediante intimidação (...) É um sistema de governo que emprega o terror para enquadrar a sociedade e que conta com o respaldo dos setores dominantes, mostrando a vinculação intrínseca entre Estado, governo e aparelho repressivo". ${ }^{13}$

Para isto, se desenvolveu um grande e complexo sistema, com muitas ramificações, mas que se estruturava numa cadeia de comando que culminava na presidência de República. De acordo com o Relatório Final da Comissão Nacional da Verdade, a estrutura da repressão poderia ser representada pelo quadro abaixo:

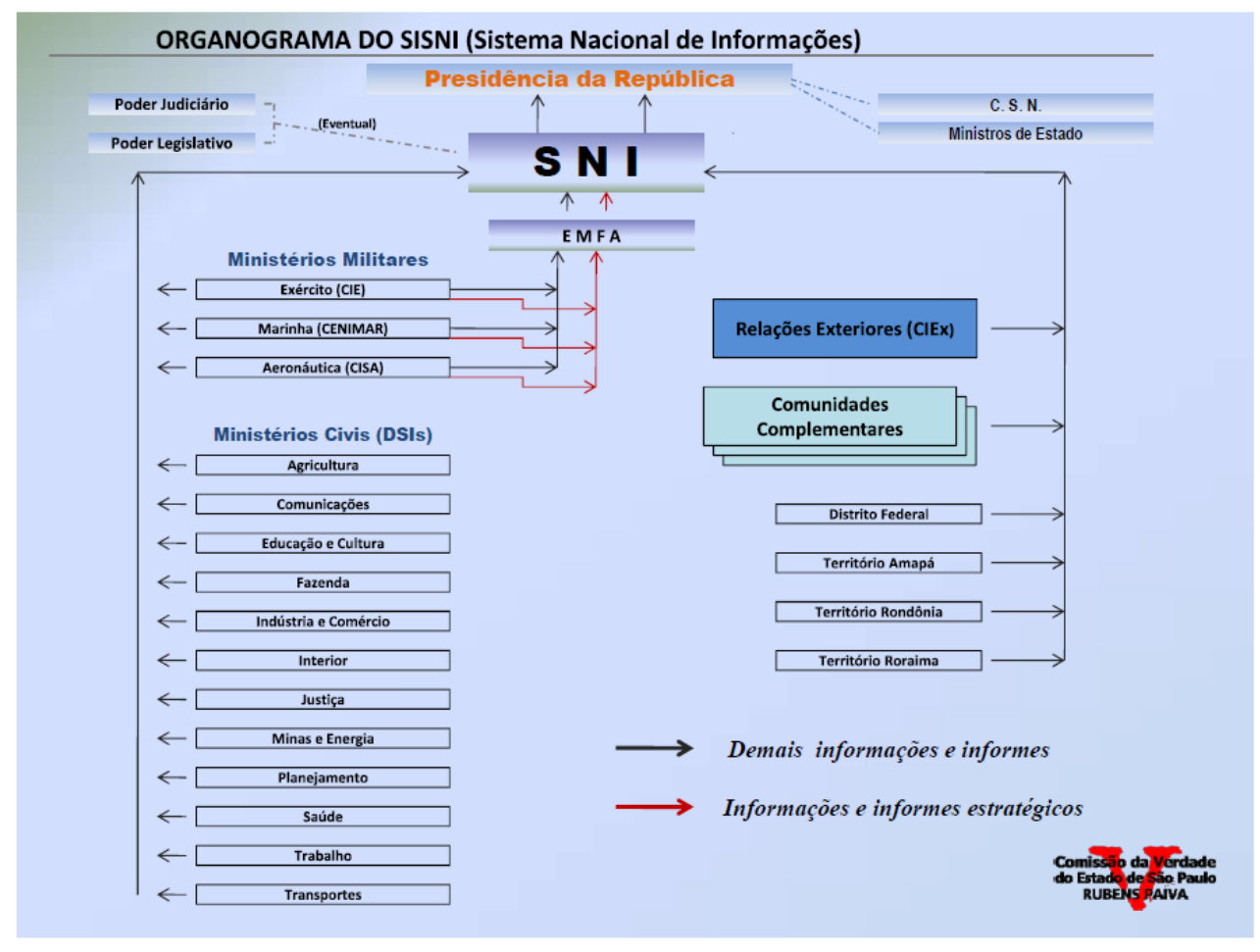

http://comissaodaverdade.al.sp.gov.br/relatorio/tomo-i/downloads/SISNI3.pdf

Neste quadro, se apresenta o Sistema Nacional de Informações (SNI), que coloca em movimento o Terrorismo de Estado. O Sistema Nacional de Informações (SISNI), reunia o conjunto de órgãos que se limitavam à de produção de informações, que depois seriam encaminhadas ao Serviço Nacional de Informações, instituição que analisava e processava estas informações e estava hierarquicamente abaixo apenas da Presidência da República, de modo que o SNI se reportava apenas ao ditador do momento.

Logo abaixo do SNI, vemos o Estado Maior das Forças Armadas, os Ministérios Militares e seus respectivos centros de informações, do Exército (CIE), Marinha (Cenimar) e Aeronáutica (Cisa). Esta estrutura tem particular importância, pois a partir delas ficam explícitas as ramificações ilegais e clandestinas no aparato repressivo, ao serem identificados centros de tortura e desaparecimento vinculados aos serviços de informações militares. É o caso da já mencionada Casa da Morte, em Petrópolis, no Rio de Janeiro, da Fazenda 31 de março de 1964 no bairro de Parelheiros, na periferia da cidade de São Paulo, entre outros centros.

13PADRÓS, E. A. Como el Uruguay no hay... Terror de Estado e Segurança Nacional. Uruguai (1968-1985): do Pachecato à ditadura civil-militar, Doutorado em História Universidade Federal do Rio Grande do Sul, Porto Alegre, 2015. 
Ao Estado Maior das Forças Armadas vinculava-se o Centro de Operação de Defesa Interna CODI e seu braço operacional a Divisão de Operação de Informações - DOI. Cada uma das Armas possuía os seus sistemas CODI-DOI. Na cidade de São Paulo, por exemplo, uma das operações repressivas mais conhecidas é a Operação Bandeirante, submetida ao II Exército.

Já os Ministérios Civis possuíam uma Divisão de Segurança e Informação em cada ministério que, por sua vez, se ramificavam e Assessorias Especiais de Segurança e Informação - as AESIs, que funcionavam em universidades, empresas estatais, autarquias e etc. Assim como os centros clandestinos de detenção, tortura e desaparecimento (a estrutura ilegal) os DOIs e as AESIs cumpriam a mesma função mas, apesar de secretas e atuarem nas sombras, eram estruturas oficiais.

Hoje as pesquisas sobre a ação das AESIs em universidades, empresas estatais e mesmo estruturas organizadas em empresas privadas vão trazendo à tona um volume até pouco tempo desconhecido do grande público e mesmo de uma parcela dos pesquisadores. ${ }^{14}$

Esta estrutura que foi suscintamente apresentada possui, ainda, muitas outras ramificações, numa complexa cadeia de comando que - diferente do que sustentaram as Forças Armadas durante longo tempo - não se trataram de excessos cometidos individualmente pelos agentes da repressão nos mais baixos escalões. Ao contrário, tratava-se de uma cadeia de comando fechada que culminava na Presidência da República.

\section{A guerrilha do Araguaia e o aporte arqueológico}

Grande parte das organizações de combate à ditadura brasileira atuou nas cidades, e sobre elas se abateu uma feroz repressão que teve seu ápice entre 1970-1971. Apesar da maioria destas organizações preconizarem a importância da organização da luta no campo, poucas foram as que tiveram alguma estrutura desenvolvida nas regiões rurais.

O Partido Comunista do Brasil foi responsável pela mais desenvolvida experiência de guerrilha rural contra a ditadura. O PC do B propunha a organização de uma guerrilha rural mesmo durante os anos do governo democrático de João Goulart que, entretanto, não passou de uma proposição teórica. Foi apenas com o golpe em 1964, que a agremiação política passou de fato à se concentrar na preparação para a luta rural, e escolheu como palco da ação uma região fronteiriça entre os estados do Pará, Maranhão e Goiás (a partir de 1988, estado do Tocantins) e a partir de 1966, passou a enviar seus militantes.

A região é bastante conhecida contemporaneamente por abrigar, desde os anos de 1980, os mais violentos conflitos pela posse da terra, com centenas de assassinados pelos latifundiários. Mas, na época, foi considerada pelo PC do B como uma região quase desabitada, com apenas alguns camponeses. Neste aspecto, assim como os militares, desconsiderou-se a presença de ribeirinhos, indígenas, quilombolas, entre outros grupos que habitavam a região.

Costuma-se apresentar a guerrilha do Araguaia em três campanhas, desenvolvidas entre 1972 e 1974, numa perspectiva que historiciza a guerrilha a partir de marcos estabelecidos pela ação militar. Contudo, o PC do B, conforme já foi dito, passou a atuar na região já a partir de 1966.

O partido criou três destacamentos militares, além de uma comissão central. A estratégia do grupo foi a de se aproximar da população, inclusive buscando adotar seu modo de vida, ao mesmo tempo em que desenvolviam um trabalho de politização com os camponeses.

Entre os anos de 1966 e 1972 o PC do B conseguiu enviar pouco mais de 70 militantes para a região que, além de organizar os destacamentos, também mapeou a área, investigando os melhor

\footnotetext{
${ }^{14}$ Ver, por exemplo: SILVA, Jussaramar, A usina de Itaipu e a Operação Condor: o outro lado das ações bilaterais BrasilParaguai (1973-1987), Mestrado em História, Pontifícia Universidade Católica de São Paulo, 2010.
} 
esconderijos, as fontes de suprimento de água e alimentos principais e secundárias, além de desenvolver croquis e montar "Pontos de Apoio" - locais na mata em que foram escondidos remédios, alimentos, armamentos, para uso dos guerrilheiros durante as batalhas ou fugas.

Em 1972 os militantes foram descobertos, mas o Exército acreditou que se tratavam de fugitivos das cidades, que procuraram a região para se esconder. Entretanto, após algumas investidas frustradas do Exército contra o grupo, os militares recuaram e passaram a desenvolver um amplo trabalho de inteligência.

Os chamados "E-2", militares que atuavam na área de informação, foram deslocados para a região. Estes andavam descaracterizados e portavam documentos falsos, além de uma "história de cobertura", isto é, criavam personagens que poderiam ser compradores de terras, técnico em telecomunicações, comerciantes com pequenos comércios na região, entre outros. Nestas atividades, os militares observavam a população e ouviam suas histórias, e nesta operação conseguiram dimensionar melhor a guerrilha, além da dinâmica que esta estabelecia com a população local.

Outra "atividade de cobertura" que merece menção foi a operação de Assistência Cívico-Social ACISO, forneceu à população serviços médicos, odontológicos, além de serem emitidos RGs e Certidões de Nascimento. É importante frisar que uma parcela importante dos moradores não tinha documentos e a região era marcada pela ausência do poder público no que se referem às demandas básicas de atendimento social, tais como, postos de saúde, hospitais, escolas etc. O Estado só aparecia aos olhos daqueles camponeses como agente repressor.

Esta atividade permitiu às Forças Armadas mapear os moradores da cidade, conhecer seu trabalho, seu local de moradia, seus nomes e, principalmente, as possibilidades de apoiar à guerrilha. Em muitas ocasiões, para "matar a guerrilha de fome" e impedir que os guerrilheiros se alimentassem dos produtos das roças dos camponeses, o Exército queimou as plantações e expulsou moradores.

Entre as atividades de inteligência, também esteve a prisão de mais de 300 moradores da região na sede do Departamento Nacional de Estradas de Rodagem - DNER, naquele momento utilizada como instalação militar e conhecida como "Casa Azul". Naquela instalação, inúmeros moradores foram torturados, com os mesmos métodos conhecidos nas cidades. Contudo, em áreas rurais, somam-se outras formas de seviciamento, uma delas recorrentemente mencionadas pelos moradores, o "buraco do Vietnã". Tratava-se de um buraco no chão, com uma grade de ferro por cima. Lá era colocado o preso após ser torturado, "onde passava dias, recebendo diariamente sol, chuva e sereno, e realizando ali mesmo suas necessidades fisiológicas, em um local infestado de insetos e animais rasteiros." ${ }^{15}$

Em 1973, já munidos de informações e já tendo prendido alguns guerrilheiros (alguns dos quais ainda hoje são tidos como desaparecidos), o Exército deu início à Terceira Campanha, da qual a ordem vinda da presidência da República, era que ninguém poderia sair vivo. Colocando em prática a ordem dos generais de Brasília, as Forças Armadas no Araguaia organizaram a ação de repressão que seria o mais lembrado episódio entre os eles, conhecido pela grotesca alcunha de "Chafurdo do Natal". Tratou-se de um massacre contra guerrilheiros que foram pegos de surpresa e executados, sem combate. Naquela ocasião foi assassinado o líder da guerrilha, Maurício Grabois.

Maurício Grabois deixou um importante registro do dia a dia da guerrilha, que se encerra abruptamente em 25 de dezembro de 1973, data do "chafurdo do Natal". Trata-se de um diário que ficou desaparecido por mais 30 anos, e fornece dados pouco conhecidos até então, como a

\footnotetext{
${ }_{15}$ MECHI, Patrícia Sposito. Protagonistas do Araguaia: trajetória, representações e práticas de camponeses, militantes e militares na guerrilha, Rio de Janeiro, Arquivo Nacional, 2015.
} 
alimentação dos guerrilheiros, as dificuldades enfrentadas, em particular pelo adoecimento frequente e as debilidades materiais e humanas que se abateram sobre o grupo.

Após o massacre do "Chafurdo do Natal", os militares passaram a atuar em equipes menores, caçando os guerrilheiros remanescentes que eram invariavelmente executados. $\mathrm{O}$ número de guerrilheiros assassinados se aproxima dos 70 . Somando-se aos assassinatos nas cidades, o PC do $\mathrm{B}$ foi a organização com o maior número de baixas durante a ditadura.

Esta apresentação sintética da dinâmica da guerrilha permite que apontemos algumas das atividades já desenvolvidas com o aporte da arqueologia, assim como é possível apontar uma série de potenciais pesquisas futuras.

A movimentação em torno do esclarecimento das circunstâncias das mortes e desaparecimentos, seja na guerrilha do Araguaia, seja em outros episódios da ditadura, tem sido protagonizada pelas organizações de familiares e teve início antes do término da ditadura.

No caso da guerrilha do Araguaia, a atuação dos familiares foi responsável direta pela aprovação, em 1995, da Lei n ${ }^{\circ}$ 9140, de dezembro de 1995, que resultou numa missão na região dirigida pela Comissão Especial dos Mortos e Desaparecidos Políticos, criada no âmbito do Ministério da Justiça. Nesta missão, foi contratada a E.A.A.F. - Equipo Argentino de Antropologia Forense, já que à época não existia no país equipes de arqueólogos com o mesmo know-how da equipe argentina, adquirida nos anos anteriores, durante os trabalhos de resgate e identificação de restos mortais de militantes assassinados naquele país.

$\mathrm{Na}$ ocasião, as escavações da equipe localizaram os restos mortais de duas pessoas: os de Maria Lucia Petit, identificada em 1996, e Bergson Gurjão Farias, que, apesar de encontrado em 1995 só foi identificado em 2009.

Um segundo momento de investigações, baseadas nas recomendações da equipe argentina, foram feitas no ano de 2001, desta vez por uma equipe brasileira. Primeiramente foram levantadas informações por meio de depoimentos de moradores do local que tiveram contato com a guerrilha; com base em pontos identificados nestes depoimentos foi que se realizaram as escavações. Durante a investigação, identificaram-se quatro bases militares principais e oito secundárias. As bases foram assim descritas:

1. Na cidade de Marabá - PA, mediante a utilização de 3 imóveis: sede do DNER (identificada pelos depoentes como "Casa Azul"), sede do INCRA, e um presídio militar (da PM ou do antigo grupamento de Tiro de Guerra, a depender da fonte). As instalações de Marabá foram utilizadas para interrogatórios e prisão de suspeitos de participar ou colaborar com os guerrilheiros, e possuíam pista de pouso;

2. Na localidade da Bacaba, sita no km. 68 da Rodovia Transamazônica (Município de São Domingos do Araguaia - PA), no local em que ficava o canteiro de obras utilizado pela construtora Mendes Junior na construção dessa rodovia. Nessa base havia pista de pouso, e uma grande área para a detenção de camponeses suspeitos, além de alojamentos para os militares e prisões para interrogatórios;

3. Na cidade de Xambioá (então Estado de Goiás, hoje Estado de Tocantins), às margens do Rio Araguaia. Também tinha pista de pouso e funcionou como prisão e local de interrogatórios. Foi a base das operações pelo Rio Araguaia;

4. Na cidade de Araguaína, então Estado de Goiás, hoje Tocantins. ${ }^{16}$

\footnotetext{
16 GRUPO DE TRABALHO ARAGUAIA. Relatório de conclusão. 04 de novembro de 2011, fl 22. Disponível em: http://2ccr.pgr.mpf.gov.br/coordenacao/grupos-de-trabalho/justica-detransicao/relatorios-1/relatorio-final-gta2011/Relatorio\%20Final\%20de\%202011.PDF acessado em: 10 de julho de 2012.
} 
As informações desse relatório sobre essas bases militares permitiram que se desenvolvessem pesquisas posteriores na região, promovidas pela Comissão Nacional da Verdade. Atualmente, a base militar identificada na cidade de Marabá, é considerada um dos centros clandestinos de tortura e desaparecimentos, identificados oficialmente em 2014, mas cuja existência, os estudiosos e familiares já sabiam há alguns anos.

Não foram encontradas evidências de sepultamento nas bases militares identificadas, possivelmente em decorrência das mudanças ocorridas na paisagem depois de passados mais de quarenta anos e, principalmente, pela realização da "Operação Limpeza" após o fim da guerrilha, operação em que os militares regressaram à região para destruir as provas e apagar vestígios dos crimes ali praticados.

O Estado Brasileiro em 2010 foi condenado pela Corte Interamericana de Direitos Humanos órgão da Organização dos Estados Americanos - pela guerrilha do Araguaia. Segundo a sentença do órgão, o país deve prestar contas sobre "do paradeiro das vítimas e identificar e entregar os restos mortais aos seus familiares, além de prestar atendimento médico, psicológico e psiquiátrico quando necessário" 17.

Esta condenação ensejou, a retomada dos trabalhos de esclarecimento dos desaparecimentos ocorridos no Araguaia. Foi criado o Grupo de Trabalho Araguaia (GTA), sob a coordenação da Secretaria de Direitos Humanos da Presidência da República (SDH/PR) e Ministérios da Justiça e Defesa. Durante sua atuação, entre 2011 e 2015 o GTA resgatou mais de 27 ossadas, mas nenhuma foi identificada. Após 2015, com o golpe contra a presidenta Dilma Roussef, os trabalhos no Araguaia foram paralisados. Além das ossadas, também foram encontrados vestígios materiais nas escavações que podem revelar aspectos ainda não esclarecidos das práticas repressivas, "tais como garrafas, medicamentos, projéteis, pilhas, recipientes de comida vazios e até mesmo um jipe". O GTA aponta que tais objetos são indícios da existência de uma base de comunicação militar no local ${ }^{18}$.

\section{Considerações Finais}

Neste artigo procuramos fazer uma breve reflexão sobre alguns aspectos da atividade repressiva criminosa levada à cabo pelas ditaduras militares na América Latina, enfocando particularmente a ditadura brasileira, e refletindo também sobre caminhos para aprofundar a compreensão de tais aspectos.

Nesse sentido, buscando indicar que a tentativa de manter-se como uma atividade clandestina, nas sombras, os crimes de lesa-humanidade como prisões arbitrárias, torturas e desaparecimentos, levou à uma prática de destruição ou não produção de documentos, coloca ao pesquisador o desafio de um diálogo interdisciplinar para desvendar este passado.

Negando o discurso sustentando pelos militares, sobre os crimes praticados serem "excessos" ou "invenções da esquerda", os testemunhos das vítimas evidenciavam outra realidade. A arqueologia surgia, então, atuando em sintonia com os setores defensores dos direitos humanos apresentando um contra discurso através das evidências materiais. As ossadas, mas também os projéteis, os frascos de remédio, as paredes com inscrições de presos nos cárceres clandestinos desmontavam a farsa dos discursos oficiais sobre a não existência de tais práticas. Para exemplificar como a arqueologia pode contribuir com o desvelamento de tais crimes, tratamos sucintamente de sua utilização no resgate das ossadas na região da guerrilha do Araguaia.

\footnotetext{
${ }^{17}$ MECHI, Patrícia Sposito, "Contra a revolução, a barbárie", Revista de História da Biblioteca Nacional, Dossiê Guerrilhas, N. 90, março/2013.

18 GRUPO DE TRABALHO ARAGUAIA. Relatório de conclusão. 04 de novembro de 2011, fl 22. Disponível em: http://2ccr.pgr.mpf.gov.br/coordenacao/grupos-de-trabalho/justica-detransicao/relatorios-1/relatorio-final-gta2011/Relatorio\%20Final\%20de\%202011.PDF acessado em: 10 de julho de 2012.
} 
Entretanto, o resgate da memória das ditaduras e o combate à perpetuação das violências praticadas no período, dependem de políticas públicas que nas duas últimas décadas foram objeto de grande esforço, feito principalmente pelos familiares dos desaparecidos políticos, junto ao Estado brasileiro. Atualmente, as comissões em instâncias governamentais foram desfeitas ou tiveram seus membros substituídos, ou ainda seus trabalhos paralisados. Em tempos de ascensão de grupos neofacistas, o avanço na seara dos direitos humanos não apenas estancou, mas regrediu francamente e os recursos para novas expedições e estudos desapareceram. O Estado brasileiro neste momento não empreende nenhum esforço neste sentido, mesmo sendo demandado pelos familiares. Apesar do cenário desanimador, esta é uma história que precisa ser resgatada, contada, esclarecida, para que não se esqueça, para que nunca mais aconteça. 